\title{
COMPARATIVE INSIGHTS INTO HYDROGEN ABSTRACTION OF CCL3H BY SMALL OXYGEN-CONTAINING ANIONS MO- WITH M = BE, B, AND AL
}

\author{
LIANG JUNXI ${ }^{*}$, ZHANG FUPENG, DUAN YU, BAI JUN, SU QIONG ${ }^{*}$, LI ZHENHUA AND ZHANG LILI \\ Key Laboratory of Environment-Friendly Composite Materials of the State Ethnic Affairs Commission, Gansu Provincial Biomass Function Composites \\ Engineering Research Center, Key Laboratory for Utility of Environment-Friendly Composite Materials and Biomass in University of Gansu Province, \\ College of Chemical Engineering, Northwest Minzu University, Lanzhou, Gansu 730030, China.
}

\begin{abstract}
In the present work, the considered hydrogen abstraction (HAT) reactions of $\mathrm{CCl}_{3} \mathrm{H}$ molecule driven by three different small anions $\mathrm{MO}^{-}(\mathrm{M}=\mathrm{Be}, \mathrm{B}$, and $\mathrm{Al})$ have been investigated using electronic structure calculations. While full geometry optimizations were operated to locate all of the relevant stationary points using the DFT-BHandHLYP/aug-cc-pVTZ level, the potential-energy profiles were constructed using the coupled-cluster theory with extrapolation to complete basis set $\mathrm{CCSD}(\mathrm{T}) / \mathrm{CBS}$. Our theoretical findings suggest that the most favored pathway determined for the HAT reactions mainly stems from the $\mathrm{MO}^{-}$type, namely, for

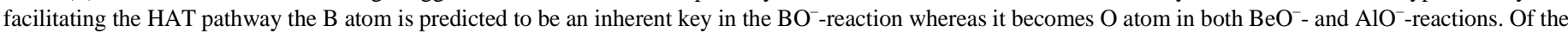
three favored pathways obtained here, the activations of the $\mathrm{CCl}_{3} \mathrm{H}$ in the presence of both $\mathrm{BeO}^{-}$and $\mathrm{AlO}^{-}$anions are significantly efficient, in which the energy barrier for the cleavage of the $\mathrm{C}-\mathrm{H}$ bond with the assistance of $\mathrm{BeO}^{-}$was to be relatively low. Again, through the transition state theory the rate constants at $298-1000$ $\mathrm{K}$ are also evaluated for the most favored HAT reactions studied here, indicating the lower the temperature, the faster the $\mathrm{BO}^{-}$chemical reaction.
\end{abstract}

Keywords: Diatomic anion; H-atom abstraction; quantum chemical calculation.

\section{INTRODUCTION}

Nowadays, making widely use of efficient chemical process to achieve cleavage of the strong organic bonds is still a major issue for academic challenge. Of the many possible agents for organic bonds activation, the gas-phase anions, in particular, the diatomic anions, continues to attract the researcher's attention, such as reactions of $\mathrm{RCl}$ ( $\mathrm{R}=$ methyl, ethyl, isopropyl, and tert-butyl) with $\mathrm{ClO}^{-}$anion, [1, 2] hence largely viewed as a prospective alternative for the expensive metal-based catalysts used for organic bonds activation. In such case, reproduction of the required diatomic anions is of very important. In this work we deal with a class of possible diatomic anions through replacing of the $\mathrm{Cl}$ atom in anion $\mathrm{ClO}^{-}$using some available elements.

It is known that when neutral diatomic compounds provide wide variety of opportunities for investigations of the unusual bonding characteristics, the corresponding anions studies also have received considerable interest. [3-9] For example, addition of an electron for $\mathrm{BeO}$ forming $\mathrm{BeO}^{-}$may generally exhibit a much slighter lengthening in the bond but a great larger decrease in the vibrational frequency. [10, 11] However, nature of the ionic bonding was apparently enhanced in the ground state $\mathrm{AlO}^{-}$electron configuration. [12] As an insight for regarding periodic trends, although the $\mathrm{B}$ and $\mathrm{Al}$ atoms are definitely categorized as the same group, possessing almost identical s-p excitation energies, [13] the electronic properties of the $\mathrm{BO}^{-}$anion were not yet available in experiments. [14] Prompted to these findings, together with reminiscence of the boron atom that possesses unique and diverse chemistries due to its electron deficiency [15], in this paper we set out a quantum chemical simulation to obtain a better understanding toward the characters of the $\mathrm{BO}^{-}$anion with the aid of an investigation of the $\mathrm{CCl}_{3} \mathrm{H}+\mathrm{BO}^{-}$reaction, representing a continuation of our interest in boron chemistry.

Most of previous anions investigations on the bonds activation are primarily controlled by their reactions of bimolecular nucleophilic substitution $\left(\mathrm{S}_{\mathrm{N}} 2\right)$, however, probability of the HAT mechanism for the type of $\mathrm{X}^{-}+\mathrm{CH}_{3} \mathrm{Y}$ reaction has typically reported as well, in which the HAT is usually endothermic for these reactions and does not occur at low collision energies. [16, 17] The importance of HAT at the low energies is evidently illustrated by studies of the $\mathrm{OH}^{-}+\mathrm{CH}_{3} \mathrm{I}$ reaction. [18, 19] Obviously, the resulting HAT should be an available pathway for the ongoing anionic reactions, which allows one to probe the intrinsic reactivity of the anions. Moreover, large amounts of studies on the reactions of carbene radical anions have already discovered occurrence of the remarkable HAT. [20-27] Therefore, we were strongly curious about whether the hydrogen abstraction (HAT) is a general pathway for studies of the anionic reactions? Recently, we explicitly predicted reaction mechanism of $\mathrm{CY}_{3} \mathrm{H}+\mathrm{XO}^{-}(\mathrm{X}, \mathrm{Y}=$ $\mathrm{F}, \mathrm{Cl}$, and $\mathrm{Br}$ ) by means of the HAT pathway, proposing activation of $\mathrm{C}-\mathrm{H}$ bond in $\mathrm{CY}_{3} \mathrm{H}$ increases as $\mathrm{Y}$ goes from $\mathrm{F}$ to $\mathrm{Br}$ and decreases as $\mathrm{X}$ from $\mathrm{F}$ to $\mathrm{Br}$. [28] Simultaneously, our investigations performed for the type reactions have reported potential energy surfaces (PESs) with a central barrier that separates the potential minima for the pre- and postreaction ion-dipole complexes, except of the $\mathrm{FO}^{-}$reaction. An intriguing question is whether substituent $\mathrm{X}$ in the halogen-oxygen anion $\mathrm{XO}^{-}$can be changed that the PES no longer retains two wells, then, the substituent-activity relationship controlling the reaction pathways has inevitably intrigued our interest.

However, to the best of our knowledge, there are currently less available works for the $\mathrm{CCl}_{3} \mathrm{H}$ HAT reactions induced by the modeling $\mathrm{MO}^{-}$anions with different active sites, where $\mathrm{M}$ is metal atom. More important, the associated metal atom in the family $\mathrm{MO}^{-}$lying positively charges can overcome their dangling bond, [29] thus dramatically changing corresponding electronic and chemical features, which are not observed in the halogen-oxygen anions. For the reason stated above, a comparative HAT reaction model, $\mathrm{MO}^{-}+\mathrm{CCl}_{3} \mathrm{H} \rightarrow \mathrm{CCl}_{3}{ }^{-}+\mathrm{MOH}$ and $\mathrm{H}-\mathrm{MO}(\mathrm{M}=\mathrm{Be}, \mathrm{B}$, and $\mathrm{Al})$, is deservedly considered for our present studying system, as they yield good insights regarding periodic trends. Our computed results shed new light on the reactivity abilities of the novel amphiproticelements-containing anions to achieve the $\mathrm{C}-\mathrm{H}$ bond activation, and thereby suggest directions for the search for the anions as potential catalysts for dehydrogenation processes.

\section{METHODOLOGY}

All electronic structure computations are fully conducted using both density functional theory (DFT) and wave-function methods implemented in the Gaussian 03 suite of program. [30] Noted that the popular DFT-BHandHLYP functional [31] belongs to a better functional for calculations of the $\mathrm{H}$-atom transfer pattern. [28, 32] Moreover, this BHandHLYP is previously proved to be very efficient for the estimations of the molecular energies and geometries. [3335] Although the recent studies show that it was fairly advantageous to use DFT-B3LYP wave function as the reference set for the $\mathrm{BeO}^{-}$higher-order calculation, [36] our present BHandHLYP/aug-cc-pVTZ computation gives a $1.235 \AA$ bond length for the ground state of $\mathrm{BO}^{-}\left({ }^{1} \Sigma^{+}\right)$, which is in excellent agreement with the B3LYP/aug-cc-pVTZ result (1.234 $\AA$ ) [37], especially the experimental measurement $1.236 \pm 0.001 \AA$ [38]. With the above exposures, the hybrid BHandHLYP functional should be very appropriate and reliable for investigations of the $\mathrm{CCl}_{3} \mathrm{H}+\mathrm{MO}^{-}$systems and thus used to optimize the geometries of all stationary structures studied in this paper, in conjunction with Dunning's all-electron basis set (aug-cc-pVTZ) [39]. Meanwhile, this DFT method has also been used to characterize the distinctive nature of the stationary points on PES, in which the minima were properly confirmed with positive frequencies and the transition state structure had single imaginary frequency. The intrinsic reaction coordinate (IRC) was often carried out to track the minimum energy paths from transition state to the corresponding minima [40]. The natural population analysis (NPA) has been expressly made with the natural bond orbital (NBO) method [41] to obtain significant insights into the bonding properties. Furthermore, much more accurate $\operatorname{CCSD}(\mathrm{T}) / \mathrm{CBS}$ quality energies are reasonably extrapolated by using the open-source Psi4 program [42], in which there is a driver that does the extrapolation procedure automatically. 
Rate coefficients over the temperature range 298-1000 K were typically calculated for the favorable pathways found in the title reactions using the conventional transition-state theory: [43, 44].

$$
k(T)=\kappa(T) k^{\mathrm{TST}}(T)=\kappa(T) \frac{k_{B} T}{h} e^{\frac{-\Delta G^{*}}{R T}}
$$

where $k_{B}$ and $h$ are the Boltzmann and Planck constants respectively; the transmission coefficient $\kappa(T)$ was effectively evaluated through the Wigner method [45]. $\kappa^{W}(T)$ is given by:

$$
\kappa^{W}(T)=1+\frac{1}{24}\left[\frac{h \operatorname{Im}\left(v^{\neq}\right)}{k_{B} T}\right]^{2}
$$

where $v^{\neq}$is the TS imaginary frequency.

\section{RESULTS AND DISCUSSION}

With regard to the title reactions presented here, Fig. 1 illustrates clearly the BHandHLYP optimized geometrical shapes marked with some key parameters, in which precursor complex, transition state, product complex, and final product are artificially denoted by the labels IM1-Y, TS1-Y, IM2-Y, and P-Y, respectively, where $\mathrm{Y}$ stands for either $\mathrm{OM}$ or $\mathrm{MO}$, indicating the $\mathrm{C}-\mathrm{H}$ bond activation of $\mathrm{CCl}_{3} \mathrm{H}$ by the $\mathrm{MO}^{-}$anions can be directly induced by its $\mathrm{O}$ or $\mathrm{M}$ site. Moreover, the predicted PESs together with relevant geometries were vividly described in Fig. 2 on the basis of the CCSD(T)/CBS relative energies. Estimation of the exothermic and endothermic reactions was understandably characterized by employing enthalpies $(\Delta H)$ of formation of the products relative to the corresponding reactants. All mentioned energy values respectively summarized in TABLE S1 (Supporting Information). The previous observation shows that electron transfer from $\mathrm{K}$ atom to $\mathrm{CCl}_{3} \mathrm{H}$ molecule produces mainly the $\mathrm{Cl}^{-}$ion, [46] indicating that the $\sigma^{*}(\mathrm{C}-\mathrm{H})$ antibonding orbital is not activated. However, in this paper following the acceptor ability of the $\sigma^{*}(\mathrm{C}-\mathrm{H})$ and $\sigma^{*}(\mathrm{C}-\mathrm{Cl}$ ) orbitals (cf. Table 1), in the IM1-Y complexes the NBO second-order perturbation energy, $E^{(2)}$, for $\mathrm{LP}(\mathrm{O} / \mathrm{M}) \rightarrow \sigma^{*}(\mathrm{C}-\mathrm{H})$ is quite sensitive, proposing the greater $E^{(2)}$ values with respect to $\mathrm{LP}(\mathrm{O} / \mathrm{M}) \rightarrow \sigma^{*}(\mathrm{C}-\mathrm{Cl})$ case, to thus yield the severe $\mathrm{H}$-activation in the $\mathrm{CCl}_{3} \mathrm{H}$ molecule. In this regard, pathway of the $\mathrm{H}$-atom abstraction from $\mathrm{CCl}_{3} \mathrm{H}$ is more favorable than that of the $\mathrm{C}-\mathrm{Cl}$ bond breaking and consequently the most stable complex prefers a HAT result over the $\mathrm{C}-\mathrm{Cl}$ cleavage. Additionally, highest occupied molecular orbital (HOMO) and lowest unoccupied molecular orbital (LUMO) energies of the predicted precursor complexes (IM1-Y) were successively checked as shown visibly in Fig. 3, as well as corresponding pictures. We can see that formation of the IM1-OAl complex is preferred in thermodynamics by $3.68 \mathrm{ev} E_{\text {gap }}\left(E_{\mathrm{LUMO}}-E_{\text {Номо }}\right)$. Indeed, as clearly shown in Fig. 2, formation of the IM1-OBe should be very predominant owing to the largest complexation energies $\left(\Delta E_{\text {comp }}\right)$ among all IM1-Y complexes, in which $\Delta E_{\text {comp }}$ is defined by the relative energy of the "precursor" complex in regard to the total energy of isolated ones. Why. The more relevant information will be elucidated in detail in the following sections. Here, to make the discussions more clearly, in this paper the studied $\mathrm{CCl}_{3} \mathrm{H}+\mathrm{MO}^{-}$reactions were designedly divided into the three: (1) Reaction of $\mathrm{CCl}_{3} \mathrm{H}+\mathrm{BeO}^{-}$; (2) Reaction of $\mathrm{CCl}_{3} \mathrm{H}+\mathrm{BO}^{-}$; (3) Reaction of $\mathrm{CCl}_{3} \mathrm{H}+\mathrm{AlO}^{-}$.

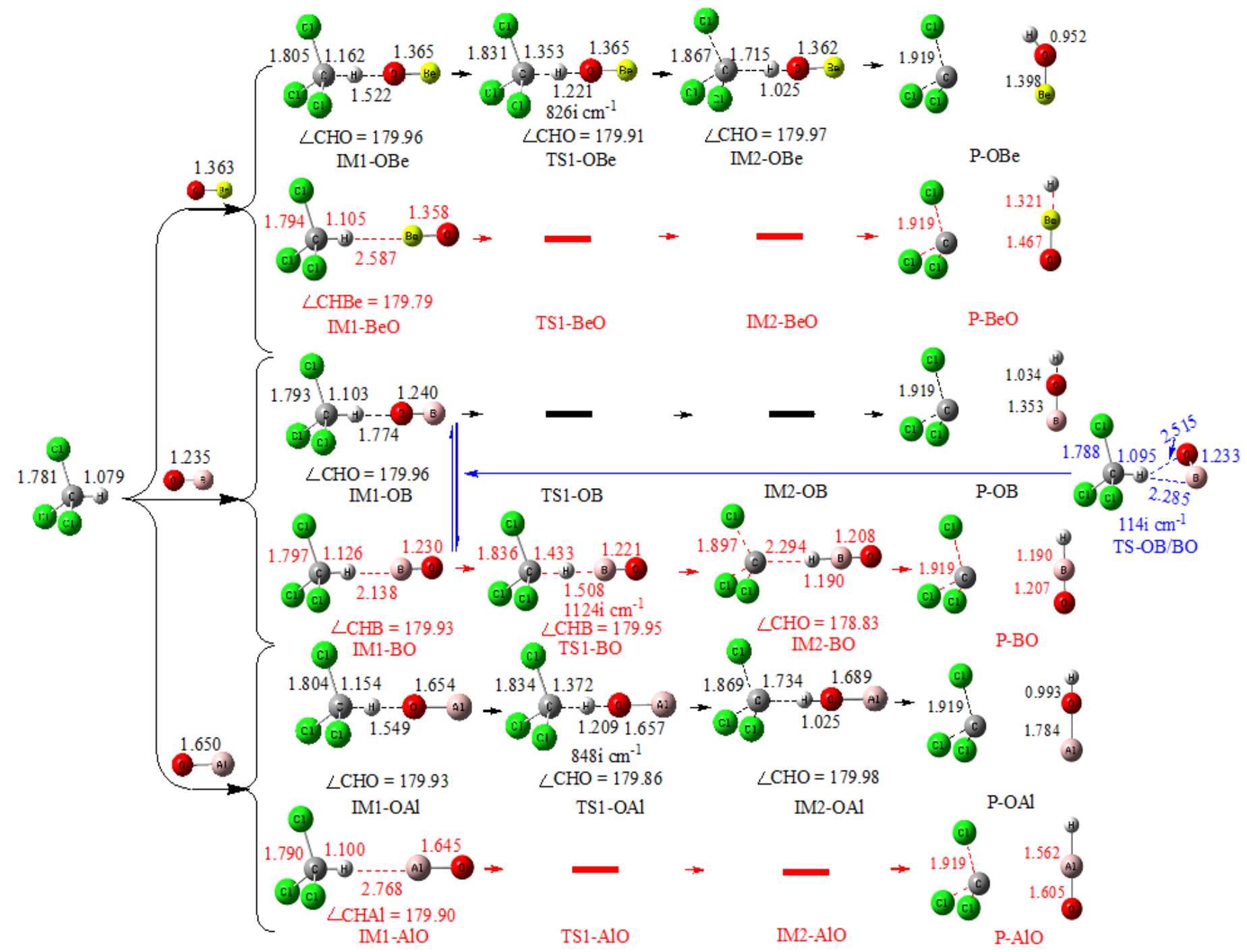

Figure 1. Optimized geometries for the HAT reactions of $\mathrm{CCl}_{3} \mathrm{H}+\mathrm{MO}^{-}(\mathrm{M}=\mathrm{Be}, \mathrm{B}$, and $\mathrm{Al})$ at the BHandHLYP/aug-cc-pVTZ level of theory, with bond distances $\AA$ and angles in degree. (The symbol “-” denotes nonexistent). 


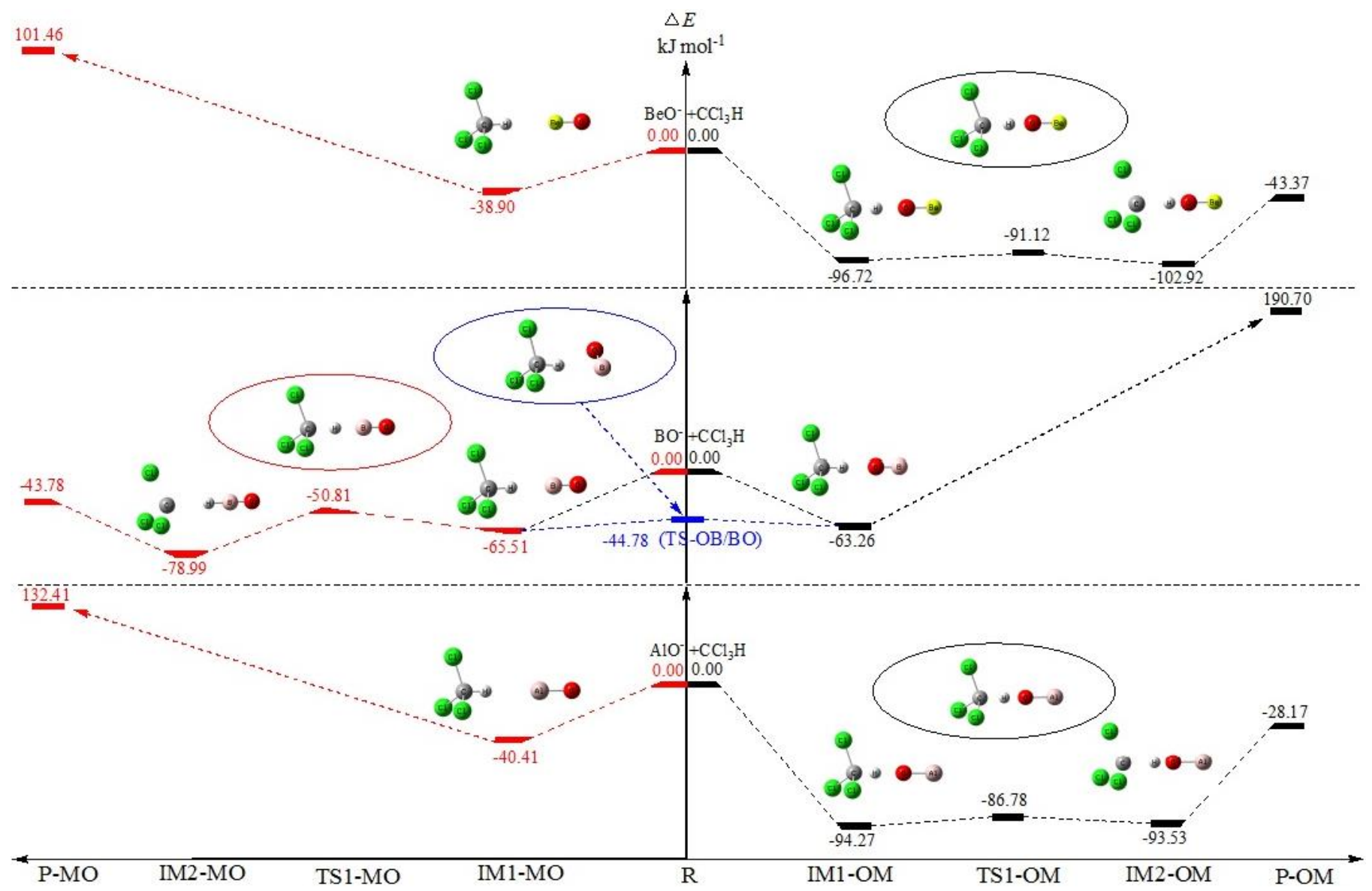

Figure 2. Energy profiles of the $\mathrm{MO}^{-}$reactions $(\mathrm{M}=\mathrm{Be}, \mathrm{B}$, and $\mathrm{Al})$. Relative energies are taken from the $\mathrm{CCSD}(\mathrm{T}) / \mathrm{CBS}$ energies summarized in $\mathrm{TABLE}$ S1 (Supporting Information).

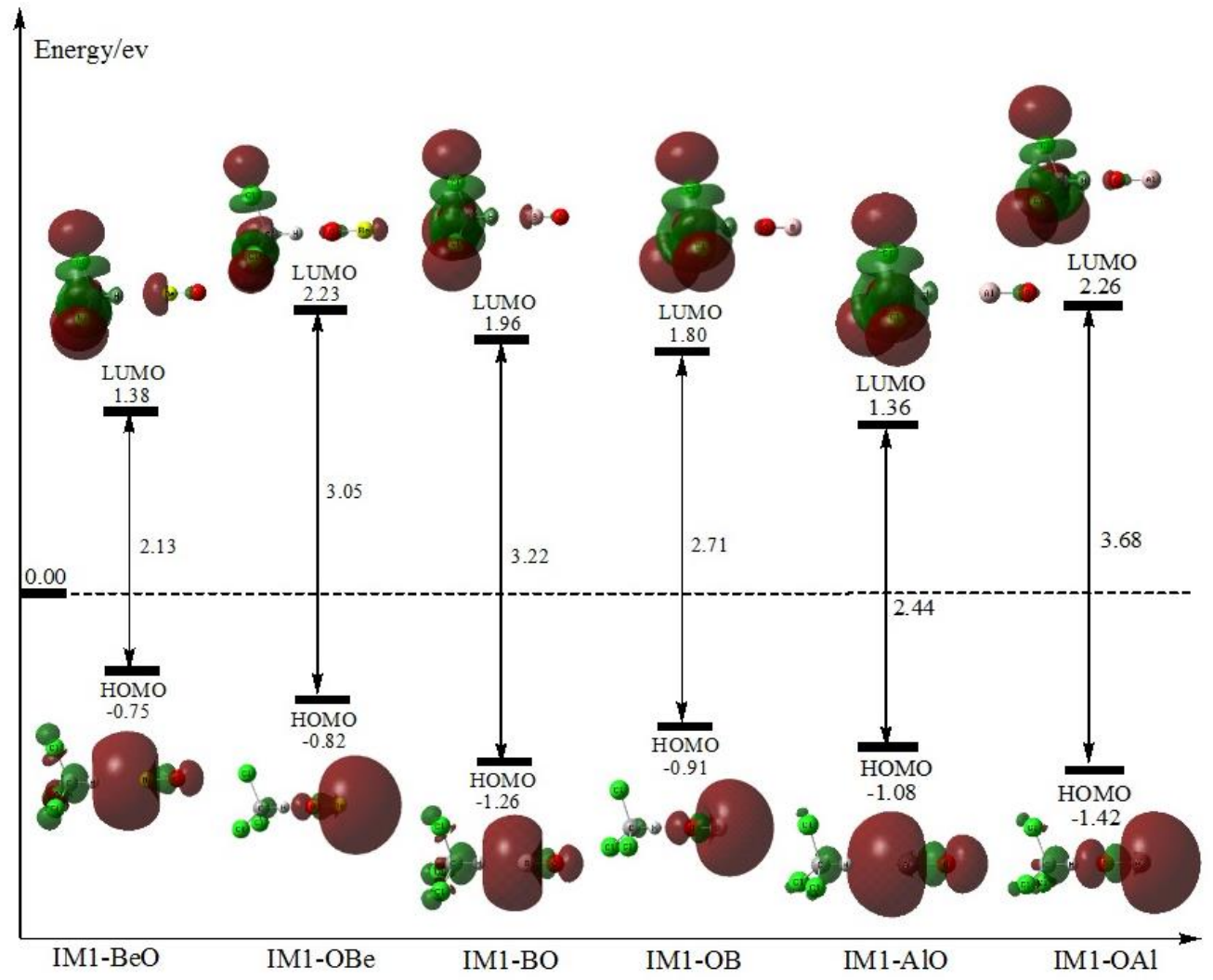

Figure. 3. Frontier molecular orbitals of the IM1-MO and IM1-OM complexes, where M = Be, B, and Al. 


\subsection{Reaction of $\mathrm{CCl}_{3} \mathrm{H}+\mathrm{BeO}^{-}$}

\subsubsection{Precursor complex}

It should be noted that the initial possible $\mathrm{C}-\mathrm{H}$ bond activation of $\mathrm{CCl}_{3} \mathrm{H}$ molecule mediated by the $\mathrm{BeO}^{-}$anion experiences firstly two alternative precursor complexes, $\mathrm{CCl}_{3} \mathrm{H}^{\cdots} \mathrm{OBe}^{-}$(IM1-OBe) and $\mathrm{CCl}_{3} \mathrm{H}^{\cdots} \mathrm{BeO}^{-}$(IM1-BeO), along the reactants' collision, as outlined distinctly in Fig. 1 together with Fig. 2. The most noteworthy feature depicted here is that the two loose ion-molecular species on PES are lying lower in energy than the separated reactants, in which the formation of the IM1-OBe is more favorable in thermodynamics thanks to its larger $\Delta E_{\text {comp }}$ when comparing the IM1-BeO case, such as $-96.72 v s-38.90 \mathrm{~kJ}$ $\mathrm{mol}^{-1}$. Besides, as demonstrated clearly in Fig. 3, the generating intermediate IM1-OBe is calculated to be $\sim 0.92 \mathrm{ev}$ larger in $E_{\text {gap }}$ than that of the IM1-BeO, implying more stabilization for the IM1-OBe, consisting with $\sim 90.00 \mathrm{~kJ} \mathrm{~mol}^{-1}$ contribution of the interaction $\mathrm{LP}(\mathrm{O}) \rightarrow \sigma^{*}(\mathrm{C}-\mathrm{H})$ exists in the IM1-OBe structure from our NBO analysis (see Table 1). Here, we failed to locate the interaction of $\mathrm{LP}(\mathrm{Be}) \rightarrow \sigma^{*}(\mathrm{C}-\mathrm{H})$ in the IM1-BeO case, despite our extensive attempt. Thus, we will mainly discuss the characters of complex IM1-OBe and its corresponding reaction, as will be shown below.

Table 1. NBO analysis obtained at the BHandHLYP/aug-cc-pVTZ level for the precursor complexes of the reactions of $\mathrm{CCl}_{3} \mathrm{H}+\mathrm{MO}^{-}(\mathrm{M}=\mathrm{Be}, \mathrm{B}$, and $\mathrm{Al})$.

\begin{tabular}{|c|c|c|c|c|c|}
\hline Species & Donor & Acceptor & $E^{(2)}\left(\mathbf{k J ~ m o l}{ }^{-1}\right)$ & $\Delta E$ (a.u.) & Fij (a.u.) \\
\hline \multirow{2}{*}{ IM1-OBe } & $\mathrm{LP}(\mathrm{O})$ & $\sigma^{*}(\mathrm{C}-\mathrm{H})$ & 90.00 & 0.94 & 0.179 \\
\hline & $\mathrm{LP}(\mathrm{O})$ & $\sigma^{*}(\mathrm{C}-\mathrm{Cl})$ & 0.79 & 0.60 & 0.014 \\
\hline \multirow{2}{*}{ IM1-BeO } & $\mathrm{LP}(\mathrm{Be})$ & $\sigma^{*}(\mathrm{C}-\mathrm{H})$ & - & - & - \\
\hline & $\mathrm{LP}(\mathrm{Be})$ & $\sigma^{*}(\mathrm{C}-\mathrm{Cl})$ & - & - & - \\
\hline \multirow{2}{*}{ IM1-OB } & $\mathrm{LP}(\mathrm{O})$ & $\sigma^{*}(\mathrm{C}-\mathrm{H})$ & 61.42 & 0.97 & 0.107 \\
\hline & $\mathrm{LP}(\mathrm{O})$ & $\sigma^{*}(\mathrm{C}-\mathrm{Cl})$ & 0.79 & 0.61 & 0.010 \\
\hline \multirow{2}{*}{ IM1-BO } & LP(B) & $\sigma^{*}(\mathrm{C}-\mathrm{H})$ & 243.97 & 0.47 & 0.153 \\
\hline & LP(B) & $\sigma^{*}(\mathrm{C}-\mathrm{Cl})$ & 2.34 & 0.14 & 0.009 \\
\hline \multirow{2}{*}{ IM1-OAl } & $\mathrm{LP}(\mathrm{O})$ & $\sigma^{*}(\mathrm{C}-\mathrm{H})$ & 119.54 & 1.14 & 0.162 \\
\hline & $\mathrm{LP}(\mathrm{O})$ & $\sigma^{*}(\mathrm{C}-\mathrm{Cl})$ & 1.13 & 0.80 & 0.013 \\
\hline \multirow{2}{*}{ IM1-AlO } & $\mathrm{LP}(\mathrm{Al})$ & $\sigma^{*}(\mathrm{C}-\mathrm{H})$ & 87.32 & 0.53 & 0.094 \\
\hline & $\mathrm{LP}(\mathrm{Al})$ & $\sigma^{*}(\mathrm{C}-\mathrm{Cl})$ & 1.09 & 0.23 & 0.007 \\
\hline
\end{tabular}

$E^{(2)}$ is the perturbative analysis hyperconjugative energy, $\Delta E$ is the energy difference between the $\mathrm{r}$ and $\mathrm{r}^{*}$ NBOs, and Fij is the Fock matrix element between the NBOs $i$ and $j$. The symbol "-_" denotes nonexistent.

\section{Complex IM1-OBe}

Let us first review the electronic structure of $\mathrm{BeO}^{-}$anion. As the point of interest for $\mathrm{BeO}^{-}$, the corresponding additional electron resides in an antibonding orbital that is primarily a mixture of $\mathrm{Be} 2 \mathrm{~s} / \mathrm{p}_{\mathrm{z}}$ and $\mathrm{O} 2 \mathrm{~s} / \mathrm{p}_{\mathrm{z}}$ hybrid atomic orbitals, giving rise to a $\mathrm{X}^{2} \Sigma^{+}$ground state. [47] And then, compared to the quartet counterpart the doublet open-shell structure of $\mathrm{BeO}^{-}$was found to be much more favored and thus used for their $\operatorname{CCSD}(\mathrm{T})$ and DFT computations in this paper. When the $\mathrm{BeO}^{-}$anion collinearly approaching $\mathrm{H}-\mathrm{CCl}_{3}$, there is very strong interaction between $\mathrm{O}\left(\mathrm{BeO}^{-}\right)$and $\mathrm{H}\left(\mathrm{CCl}_{3} \mathrm{H}\right)$, completely favoring the molecular complex IM1-OBe formation, by considering the net charges population on $\mathrm{Be}$ and $\mathrm{O}$ atoms of the $\mathrm{BeO}^{-}$. As given clearly in Fig. 4(a), the $\mathrm{Be}$ atom has an impressive positive NBO charge, whereas the net charge of the corresponding $\mathrm{O}$ atom is negative. Obviously, the $\mathrm{O}$ atom being high electronegativity tends to attract the positively charged $\mathrm{H}$ atom from the $\mathrm{CCl}_{3} \mathrm{H}$ substrate. Such gives rise to charges transfer operating from $\mathrm{BeO}^{-}$to $\mathrm{CCl}_{3} \mathrm{H}$, thus resulting in the $\mathrm{CCl}_{3} \mathrm{H}$ activation. As shown in Fig. 1, in the IM1-OBe the distance of $\mathrm{C}-\mathrm{Cl}$ bond is elongated by $0.024 \AA$ at the same time, the $\mathrm{C}-\mathrm{H}$ bond is remarkably elongated by $0.083 \AA$, with respect to the isolated $\mathrm{CCl}_{3} \mathrm{H}$ reactant. The PES profile associated with $\mathrm{IM} 1-\mathrm{OBe}$ formation found for the interaction energy between $\mathrm{BeO}^{-}$and $\mathrm{CCl}_{3} \mathrm{H}$ is $-96.72 \mathrm{~kJ} \mathrm{~mol}^{-1}$, namely, the step starting from the associated reactants $\left(\mathrm{BeO}^{-}+\mathrm{CCl}_{3} \mathrm{H}\right)$ can be very accessible without the need of extra energy. Indeed, as can be seen in discussion of 3.1.2 Section in this paper, the forming intermediate IM1-OBe located below the zero energy reference strongly facilitates the occurrence of the subsequent steps.

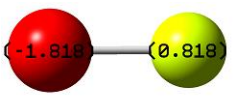

(a)

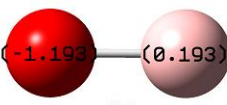

(b)

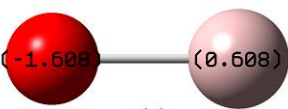

(c)
Fig. 4. NBO charges population on the anions $\mathrm{MO}^{-}$. (a) O-Be; (b) O-B; (c) $\mathrm{O}-\mathrm{Al}$

\subsubsection{Mechanism}

Fig. 2 vividly plots PES profiles illustrating the pathways of $\mathrm{H}$-atom transfer from $\mathrm{CCl}_{3} \mathrm{H}$ to $\mathrm{BeO}^{-}$. Very clearly, there are two different HAT pathways found for the reaction of $\mathrm{CCl}_{3} \mathrm{H}+\mathrm{BeO}^{-}$. The first pathway, with very striking double-well-potential character, initiated by the $\mathrm{O}$ atom of $\mathrm{BeO}^{-}$via TS1-OBe drastically undergoes dissociation of the $\mathrm{C}-\mathrm{H}$ bond in $\mathrm{CCl}_{3} \mathrm{H}$ and following formation of the $\mathrm{BeOH}$ product, with a very tiny barrier of $5.6 \mathrm{~kJ} \mathrm{~mol}^{-1}$. Here, the energy barrier is defined in this paper by energy of the least-stable transition state on PES in regard to that of the corresponding precursor complex.

Moreover, the calculated energy profiles (Fig. 2) visibly display the energy difference between IM1-OBe and IM2-OBe is very closer each other, only $\sim 6.2 \mathrm{~kJ} \mathrm{~mol}^{-1}$, however, the possible formed $\mathrm{P}-\mathrm{OBe}$ product, with respect to complex IM2-OBe, is deliberately characterized by activation energy of $59.55 \mathrm{~kJ}$ $\mathrm{mol}^{-1}$. Seemingly, the isomerization between IM1-OBe and IM2-OBe configurations takes place instead of yielding available $\mathrm{BeOH}$ product. This is very similar to results of the anionic $\mathrm{S}_{\mathrm{N}} 2$ reactions that illustrate the important role of resonances. [48-53]

In fact, the $\mathrm{P}-\mathrm{OBe}$ is located by $43.37 \mathrm{~kJ} \mathrm{~mol}^{-1}$ below the zero-energy reference, in such a way the product $\mathrm{BeOH}$ appears that can be spontaneously obtained without additional energy requirement. Alternatively, another pathway related to $\mathrm{H}$-atom abstraction from the $\mathrm{CCl}_{3} \mathrm{H}$ molecule, going forward by $\mathrm{Be}$ atom of the $\mathrm{BeO}^{-}$, may be predicted as shown in Fig. 1 clearly. The corresponding reactionenergy profile (Fig. 2) markedly indicates a single-well-potential curve path, in which the most remarkable feature is absence of the corresponding transition state. Meanwhile, a considerable endothermicity of $91.43 \mathrm{~kJ} \mathrm{~mol}^{-1}$ computed for forming of the $\mathrm{P}-\mathrm{BeO}$ product. Thereby, formation of the $\mathrm{H}-\mathrm{BeO}$ molecule happens in a difficult way, even though IM1-BeO is still located below the zero-energy level. Overall, of the two HAT pathways studied, the studied HTA reaction opened by $\mathrm{O}$ atom of $\mathrm{BeO}^{-}$is the most favorable; that is to say, the product $\mathrm{H}-\mathrm{BeO}$ is less detected in experiment.

\subsection{Reaction of $\mathrm{CCl}_{3} \mathrm{H}+\mathrm{BO}^{-}$}

\subsubsection{Precursor complex}

Upon replacement of $\mathrm{Be}$ in the $\mathrm{BeO}^{-}$anion by $\mathrm{B}$ atom, the generated $\mathrm{BO}^{-}$ion is a close-shell molecule with valence electronic configuration of $(1 \sigma)^{2}(2 \sigma)^{2}(1 \pi)^{4}(3 \sigma)^{2}$, where a single electron occupies a $\sigma$-type molecular orbital which is mainly of B $2 \mathrm{~s}$ character. Thus, the ${ }^{1} \Sigma^{+}$singlet state is normally considered as its ground structure. Our results point out that, as demonstrated distinctly in Fig. 2, two more favored intermediates IM1-OB and IM1-BO from the initial separated reactants $\left(\mathrm{BO}^{-}+\mathrm{CCl}_{3} \mathrm{H}\right)$ are spontaneously obtained without additional activation energy. Because there are substantial $\Delta E_{\text {comp }}$ found for formation of the two precursor complexes, 63.26 (IM1-OB) and 65.51 (IM1-BO) $\mathrm{kJ} \mathrm{mol}^{-1}$, which is large enough to compensate in keeping a favorable profile, discussions of the initial reactive species might be very interesting and important to provide a wealth of insights into characters of the $\mathrm{BO}^{-}$-reaction.

As a comparison of stabilization difference between the two containing-boron complexes we can clearly see that (Fig. 3) a smaller $E_{\text {gap }}$ resides preferably in the IM1-OB (2.71 ev) relative to the IM1-BO (3.22 ev), namely, the IM1-BO is more stable than the IM1-OB, which is in good agreement with our $\Delta E_{\text {comp }}$ calculations. Otherwise, it should be noted that (Table 1) the contribution of the donor of the nonbonding electrons to the $\sigma^{*}(\mathrm{C}-\mathrm{H})$ antibonding orbital in the IM1-BO structure $\left(\mathrm{LP}(\mathrm{B}) \rightarrow \sigma^{*}(\mathrm{C}-\mathrm{H})\right)$ is fairly remarkable, suggesting by $\sim 182.55 \mathrm{~kJ} \mathrm{~mol}^{-1}$ larger than the IM1-OB case $\left(\mathrm{LP}(\mathrm{O}) \rightarrow \sigma^{*}(\mathrm{C}-\mathrm{H})\right)$, which may make HAT more easily in IM1-BO and so to support more favorable $\mathrm{H}$-abstraction pathway. This result is in complete agreement with that in the $\mathrm{BO}+\mathrm{H}_{2}$ reaction [54], in which the most favorable mechanism is described using the abstraction of $\mathrm{H}$ by the $\mathrm{B}$ atom. In the following sections, we will discuss in detail the above-mentioned predictions. 


\section{Complex IM1-OB}

An ion-molecular complex IM1-OB can be firstly obtained through activation of $\mathrm{CCl}_{3} \mathrm{H}$ by the $\mathrm{O}$ atom of $\mathrm{BO}^{-}$and the corresponding geometrical shape is visibly illustrated in Fig. 1. Unlike formation of IM1-OBe found in the reaction of $\mathrm{BeO}^{-}$, as shown in Fig. 1, the $\mathrm{C}-\mathrm{Cl}$ and $\mathrm{C}-\mathrm{H}$ bonds $(\AA)$ described in the IM1-OB are slightly elongated by 0.012 and 0.024 , respectively, in regard to the isolated $\mathrm{CCl}_{3} \mathrm{H}$ molecule. Actually, although the NBO population analysis illustrates distinctly the presence of the notable negative charges (-1.193 e) on the $\mathrm{O}$ atom of $\mathrm{BO}^{-}$(see Fig. 4(b)), known as the $\mathrm{B}$ atom having deficient electrons, the $\mathrm{HOMO}(3 \sigma)$ of $\mathrm{BO}^{-}$is basically a $\mathrm{B} 2 \mathrm{~s}$ lone pair with slight $\mathrm{BO}$ antibonding character, [37] whose weak antibonding character is expected to partially cancel the bonding character. Such action does not facilitate the reaction of $\mathrm{CCl}_{3} \mathrm{H}+\mathrm{BO}^{-}$to proceed continually its following process, even though the precursor complex IM1-OB having considerable $\Delta E_{\text {comp }}$ of $63.26 \mathrm{~kJ} \mathrm{~mol}^{-1}$.

\section{Complex IM1-BO}

As just predicted above, captivity of the $\mathrm{B}$ atom in $\mathrm{BO}^{-}$for the $\mathrm{CCl}_{3} \mathrm{H}$ activation is much stronger than that of the corresponding $\mathrm{O}$ atom, thus the possible IM1-BO complex for the reaction of $\mathrm{BO}^{-}$with $\mathrm{CCl}_{3} \mathrm{H}$ that is identified rationally. As shown clearly in Fig. 1, formation of the IM1-BO complex entirely stems from a near-linear approach of $\mathrm{B}$ atom (in $\mathrm{BO}^{-}$) to the $\mathrm{H}$ atom of the $\mathrm{CCl}_{3} \mathrm{H}$ substrate. However, the computed distance between $\mathrm{B}$ and $\mathrm{H}$ atoms in the IM1$\mathrm{BO}$ is approximately $0.364 \AA$ longer than that between $\mathrm{O}$ and $\mathrm{H}$ atoms in the IM1-OB.

Indeed, as can be observed from Fig. 2, the IM1-BO is only $\sim 2.25 \mathrm{~kJ} \mathrm{~mol}^{-1}$ more stable than the IM1-OB, namely, they are quite close in $\Delta E_{\text {comp, }}$, which assume existence of a rather free isomerization process from IM1-OB to IM1-BO and the detailed discussions are well-rounded described in Section 3.2.2. Again, the $\mathrm{C}-\mathrm{H}$ bond activation of the $\mathrm{CCl}_{3} \mathrm{H}$ by $\mathrm{B}$ atom of the $\mathrm{BO}^{-}$is found to be very predominant, as displayed in Fig. 1 clearly, $\mathrm{C}-\mathrm{H}$ bond in IM1-BO is acutely elongated by $0.047 \AA$ compared to the isolated $\mathrm{CCl}_{3} \mathrm{H}$ case. Obviously, the complex IM1-BO plays a role as a key precursor complex for HAT from $\mathrm{CCl}_{3} \mathrm{H}$ to $\mathrm{BO}^{-}$, which favors the subsequent step to happen.

\subsubsection{Mechanism}

Schematic PES profile associated with possible HAT pathways for the reaction of $\mathrm{CCl}_{3} \mathrm{H}+\mathrm{BO}^{-}$is very clearly displayed in Fig. 2. As expected, there are two types of pathways found for the considered reactions, i.e., $\mathrm{CCl}_{3} \mathrm{H} \rightarrow \mathrm{OB}^{-}$and $\mathrm{CCl}_{3} \mathrm{H} \rightarrow \mathrm{BO}^{-}$. Of the two cases for the $\mathrm{C}-\mathrm{H}$ bond scission of $\mathrm{CCl}_{3} \mathrm{H}$ molecule, the former pathway is graphically characterized by a single-well reaction-energy profile, whereas the latter becomes the double-well-potential pathway. Again, formation of the product $\mathrm{P}-\mathrm{OB}$ derived from the former pathway is approved to be less preferred in energies, being an enormous endothermicity of $181.57 \mathrm{~kJ}$ $\mathrm{mol}^{-1}$, whereas in the latter the corresponding product P-BO can readily be created with an energy release of $48.44 \mathrm{~kJ} \mathrm{~mol}^{-1}$.

Those are in good accordance with some predicted studies that the energy difference between the two isomers, $\mathrm{H}-\mathrm{BO}$ (in $\mathrm{P}-\mathrm{BO}$ ) and $\mathrm{BOH}$ (in $\mathrm{P}-\mathrm{OB}$ ), is in a range of 214-244 $\mathrm{kJ} \mathrm{mol}^{-1}$. [55-61] Although the former reaction can be achieved with considerable endothermic, the $\mathrm{C}-\mathrm{H}$ bond activation with the help of the $\mathrm{O}$ atom of $\mathrm{BO}^{-}$still takes an advantage over the isolated $\mathrm{CCl}_{3} \mathrm{H}$ case, owing to favored generation of the stable precursor complex IM1-OB lying $63.26 \mathrm{~kJ}$ $\mathrm{mol}^{-1}$ below the zero-energy level. In most case, a rather free isomerization process from IM1-OB to IM1-BO via transition state TS-OB/BO may likely occur. Such behavior can be elucidated by lower barrier heights, being around $\sim 18.48 \mathrm{~kJ} \mathrm{~mol}^{-1}$, particularly, the TS-OB/BO is located beneath the zero-energy level as is clearly observed from Fig. 2. In other words, the HAT reaction of $\mathrm{CCl}_{3} \mathrm{H}$ with $\mathrm{BO}^{-}$happens mostly upon abstraction of the $\mathrm{B}$ atom of $\mathrm{BO}^{-}$forward $\mathrm{H}$ atom of $\mathrm{CCl}_{3} \mathrm{H}$, leading to the obtained the $\mathrm{H}$-BO product in preference over the final $\mathrm{BOH}$ product.

Hence, we only focus here on the pathway starting from the IM1-BO complex. As the most favored channel for reaction of $\mathrm{CCl}_{3} \mathrm{H}+\mathrm{BO}^{-}$, the pathway involving TS1-BO yielding product $\mathrm{P}-\mathrm{BO}$ is reliably characterized to be an exothermic process. Despite there is a high energy barrier of $14.7 \mathrm{~kJ} \mathrm{~mol}^{-1}$ for the HAT reaction of $\mathrm{CCl}_{3} \mathrm{H}+\mathrm{BO}^{-}$, the related TS1-BO lies now $50.81 \mathrm{~kJ} \mathrm{~mol}^{-1}$ below the separated reactants. Apparently, the HAT process via TS1-BO is unquestionably spontaneous with absence of an overall energy barrier and thus turned out to be the most favored for the reaction of $\mathrm{CCl}_{3} \mathrm{H}$ with $\mathrm{BO}^{-}$.

\subsection{Reaction of $\mathrm{CCl}_{3} \mathrm{H}+\mathrm{AlO}^{-}$}

\subsubsection{Precursor complex}

Analogous to cases of the $\mathrm{BeO}^{-}$reaction reported in our present study (Section 3.1), there also are two alternative pathways found for activation of the substrate $\mathrm{CCl}_{3} \mathrm{H}$ when $\mathrm{AlO}^{-}$attacks, emerging to have two stable precursor complex, IM1-OAl and IM1-AlO, respectively. As is observably shown in Fig. 2 , the two complexes are not only located beneath the zero-energy level, but also characterized by a relatively strong interaction, such as the predicted $\Delta E_{\text {comp }}$ being $-94.27 \mathrm{~kJ} \mathrm{~mol}^{-1}$ for the IM1-OAl and $-40.41 \mathrm{~kJ} \mathrm{~mol}^{-1}$ for the I M1-AlO. The calculated $E_{\text {gap }}$ shows (see Fig. 3 ) that the IM1-OAl is $\sim 1.24 \mathrm{ev}$ larger than the IM1-AlO, so favoring the IM1-OAl more stabilization. In other words, there exists a strong orbital interaction between the $\mathrm{p}$ orbital of $\mathrm{O}\left(\mathrm{AlO}^{-}\right)$and the $\mathrm{s}$ of $\mathrm{H}\left(\mathrm{CCl}_{3} \mathrm{H}\right)$, which is very beneficial for activation of $\mathrm{CCl}_{3} \mathrm{H}$ $\mathrm{C}-\mathrm{H} \sigma$ bond. Hence, differing from the channel coming from IM1-AlO to form $\mathrm{P}-\mathrm{AlO}\left(\mathrm{H}-\mathrm{AlO}+\mathrm{CCl}_{3}{ }^{-}\right)$product that is endothermic, the pathway starting from IM1-OAl to yield product P-OAl $\left(\mathrm{AlOH}+\mathrm{CCl}_{3}^{-}\right)$is found to be exothermic, which is in good agreement with the result that the formation of the $\mathrm{AlOH}$ more stable than that of the $\mathrm{H}-\mathrm{AlO}$. [62] As a result, the HAT reaction of $\mathrm{CCl}_{3} \mathrm{H}$ mediated by the $\mathrm{O}$ atom of $\mathrm{AlO}^{-}$, similar to the initial step of the reaction of $\mathrm{AlO}_{2}^{-}+\mathrm{H}_{2} \mathrm{O}$, [63] is more favored than that by the corresponding $\mathrm{Al}$ atom and we only report here some important properties of the IM1-OAl complex and its corresponding mechanism.

\section{Complex IM1-OAI}

Formation of the examined complex named IM1-OAl attained $\mathrm{AlO}^{-}$with electronic $\mathrm{X}^{1} \Sigma^{+}$ground state has considerably large $\Delta E_{\text {comp }}$ of $-94.27 \mathrm{~kJ} \mathrm{~mol}^{-1}$ (cf. Fig. 2), thus the process is spontaneous with absence of an overall energy barrier. Specifically, character of a substantial bonds activation found for the $\mathrm{CCl}_{3} \mathrm{H}$ moiety appears. As shown clearly in Fig. 1, comparing with the isolated $\mathrm{CCl}_{3} \mathrm{H}$ molecule, the distances $(\AA)$ of $\mathrm{C}-\mathrm{Cl}$ and $\mathrm{C}-\mathrm{H}$ bonds in the IM1-OAl are elongated by 0.023 and 0.075 , respectively. Such result that may mainly originate from the striking $\mathrm{LP}(\mathrm{O}) \rightarrow \sigma^{*}(\mathrm{C}-\mathrm{H})$ hyperconjugative effect in the IM1-OAl structure, displaying $\sim 119.54 \mathrm{~kJ} \mathrm{~mol}^{-1}$ interaction from NBO analysis collected in Table 1. Therefore, similar to the $\mathrm{BeO}^{-}$case, the $\mathrm{O}$ atom of $\mathrm{AlO}^{-}$tends to priority attraction of the positively charged $\mathrm{H}$ atom from $\mathrm{CCl}_{3} \mathrm{H}$ molecule, as the result of the notable electronegativity difference between the $\mathrm{Al}$ and $\mathrm{O}$ atoms (see Fig. 4(c)).

\subsubsection{Mechanism}

As demonstrated distinctly in Fig. 2, the HAT pathway coming from the complex IM1-OAl takes place via transition state TS1-OAl, briefly describing $\mathrm{C}-\mathrm{H}$ bond breaking and $\mathrm{O}-\mathrm{H}$ bond formation, to yield another much favored intermediate IM2-OAl. This process needs to overcome very tiny energy barrier of $7.49 \mathrm{~kJ} \mathrm{~mol}^{-1}$. If the pathway starts from IM2-OAl to IM1-OAl, an only barrier of $6.75 \mathrm{~kJ} \mathrm{~mol}^{-1}$ is preferential. Meanwhile, the transition state TS1-OAl is located well below the zero-energy level and associated with overall barrier of $-86.78 \mathrm{~kJ} \mathrm{~mol}^{-1}$ with respect to the separated reactants.

Those strongly suggest the long-lived properties for the IM1-OAl and IM2-OAl complexes and much free isomerization between them, [64] in such a way that the formation of product P-OAl happens in a difficult way. In fact, formation of the product $\mathrm{P}-\mathrm{OAl}\left(\mathrm{AlOH}+\mathrm{CCl}_{3}^{-}\right)$in this channel is energetically favored with an overall exothermic energy of $36.62 \mathrm{~kJ} \mathrm{~mol}^{-1}$, in turn, the $\mathrm{AlOH}$ molecule can be easily obtained without the need of extra energy.

\subsection{Comparisons of the most favored $\mathrm{BeO}^{-}-, \mathrm{AlO}^{-}$-, and $\mathrm{BO}^{-}$-reactions}

The most favored possible $\mathrm{HAT}$ pathways obtained for $\mathrm{BeO}^{-}, \mathrm{AlO}^{-}$, and $\mathrm{BO}^{-}$-reactions are identified as the channels emanating from complexes IM1-OBe, IM1-OAl, and IM1-BO, respectively, in which both IM1-OBe and IM1-OAl are much more stable than the IM1-BO and the $\mathrm{H}$-atom abstractions via the former two cases appear to be dominant in particular. Our MO analysis (Fig. 3) shows that the BO moiety in the HOMO of IM1-BO is primarily composed of B 2s AO with slight antibonding character between the $\mathrm{B} 2 \mathrm{~s}$ and $\mathrm{O} 2 \mathrm{p}$ AO's, whose the antibonding character is expected to partially weaken the bonding character. In contrast, the $\mathrm{BeO}$ fragment in the HOMO of IM1-OBe presents a $\sigma$ bonding $\mathrm{MO}$ composed of $\mathrm{O} 2 \mathrm{p}$ and $\mathrm{Be} 2 \mathrm{~s}$ AO's, which involves significant charges back-donation from $\mathrm{O}$ to $\mathrm{Be}$ and therefore it is of strong ionic 
character; This analogous phenomenon also found expectedly for the AlO moiety in the HOMO of IM1-OAl. Those might further suggest that both Al-O and $\mathrm{Be}-\mathrm{O}$ bonding are primarily ionic while $\mathrm{B}-\mathrm{O}$ bonding is more covalent, which is in good agreement with the experimental observation [37].

Noted that in our presented $\mathrm{MO}^{-}$anions when the $\mathrm{M}$ is fixed as same group, along with the rising atomic number, such as from $\mathrm{B}$ to $\mathrm{Al}$, it is found to be of different for the $\mathrm{MO}^{-}$to interplay with $\mathrm{CCl}_{3} \mathrm{H}$ to complete corresponding most favored HAT reaction. As shown remarkably in Fig. 2, the most favored HAT in the $\mathrm{BO}^{-}$-reaction is promoted by the $\mathrm{B}$ atom, whereas it becomes $\mathrm{O}$ atom in the $\mathrm{AlO}^{-}$-reaction. Again, compared to ability of the $\mathrm{BO}^{-}$toward the $\mathrm{C}-\mathrm{H}$ activation, the $\mathrm{AlO}^{-}$anion induces a larger reduction in energy barrier, which amounts now to $\sim 7.49 \mathrm{~kJ} \mathrm{~mol}^{-1}$. In addition, difference between the energy barriers mainly arises from that between their stability ordering. As displayed in Fig. 1, in the TS1-BO the $\mathrm{C}-\mathrm{H}$ bond length elongates to about $0.06 \AA$ compared to the TS1-OAl case and thus leads to higher barrier. Obviously, the larger the radical of $\mathrm{M}$ atom is, the more easily the $\mathrm{MO}^{-}$induced HAT reaction occurs, for example, the HAT with assistance of the $\mathrm{AlO}^{-}$has taken place rather more efficiently than that with the $\mathrm{BO}^{-}$(see Fig. 2). Nevertheless, although the higher energy barrier for $\mathrm{C}-\mathrm{H}$ cleavage pathway is revealed in the $\mathrm{BO}^{-}$-reaction, the most remarkable feature here is the absence of the overall energy barrier for the $\mathrm{C}-\mathrm{H}$ breaking. It means that this process can also be more favored and the corresponding reaction may take place quickly (see the estimations of rate constant below). On the other hand, when comparing the reactions achieved by the nearly same size $\mathrm{MO}^{-}$anions, such as the $\mathrm{BeO}^{-}$and $\mathrm{AlO}^{-}$reactions, the favored HAT found for the route is consistently induced by the $\mathrm{O}$ atom of $\mathrm{MO}^{-}$. Moreover, the energy barrier for the $\mathrm{C}-\mathrm{H}$ dissociation in the $\mathrm{AlO}^{-}$reaction is slightly higher than that in the $\mathrm{BeO}^{-}$reaction, with a maximum difference of only $\sim 1.89 \mathrm{~kJ} \mathrm{~mol}^{-1}$. Consequently, the $\mathrm{H}$-abstraction presented here takes place last along the reaction path for TS1-OAl rather than TS1-OBe. This can be well understood by considering their individual geometric characteristics such as the calculated bond orders $\%(\mathrm{C}-\mathrm{H})^{\neq}, 25 \%$ (TS1-OBe) $<27 \%$ (TS1-OAl), according to Eqns reported by Ren [65]. In contrast, the newly formed O-H bonds in the TS are obviously lengthened relative to their final equilibrium values by ca. $28 \%$ for the $\mathrm{BeO}^{-}$abstraction and ca. $22 \%$ for the $\mathrm{AlO}^{-}$abstraction. These features indicate that the $\mathrm{BeO}^{-} \mathrm{HAT}$ reaction reaches the TS relatively early, whereas the $\mathrm{AlO}^{-}$case arrives at the TS relatively late. Thus, the reaction of $\mathrm{CCl}_{3} \mathrm{H}+\mathrm{BeO}^{-}$ may have the highest exothermicity among all presented favored reactions. In summary, the various selections of the elements $\mathrm{M}$ may result in $\mathrm{MO}^{-}$to possess different activated ability, namely, the nearly same size $\mathrm{MO}^{-}$can induce stronger $\mathrm{C}-\mathrm{H}$ bond activation than the $\mathrm{MO}^{-}$with same group $\mathrm{M}$ does.

Results of the rate constants at the BHandHLYP/aug-cc-pVTZ level of theory for the most favored HAT reactions of $\mathrm{CCl}_{3} \mathrm{H}+\mathrm{MO}^{-}(\mathrm{M}=\mathrm{Be}, \mathrm{B}$, and $\mathrm{Al})$ are systematically compiled in Table 2 . For the transmission coefficient $\left(k^{\mathrm{W}}\right)$, there exists a very striking feature, as is shown clearly in Table 2 , the $k^{\mathrm{W}}$ gradually decreased with the increasing in temperature, indicating that the entropic effects became less significant for the rate constant, and thus decrease in probability of the tunneling. Also, it may be noted that contribution of the temperature for increasing rate constants of $k(T)\left(\mathrm{L} \mathrm{mol}^{-1} \mathrm{~s}^{-1}\right)$ after $k^{\mathrm{W}}$ correction is very appreciable for both $\mathrm{BeO}^{-}$and $\mathrm{AlO}^{-}$reactions with respect to $\mathrm{BO}^{-}$reaction, showing the higher the temperature, the larger the $k(T)$ value, the faster the reaction. In contrast, under the lower conditions, chemical rates of both $\mathrm{BeO}^{-}$and $\mathrm{AlO}^{-}$reactions are much smaller than that of the $\mathrm{BO}^{-}$reaction. In other words, reaction of $\mathrm{BO}^{-}+\mathrm{CCl}_{3} \mathrm{H}$ occurs strongly faster at the lower temperature. In fact, for the $\mathrm{BO}^{-}$reaction the high HAT frequency value $\left(1124 i \mathrm{~cm}^{-1}\right)$ calculated from BHandHLYP level indicates the dominating contribution of the proton movement in the reaction coordinates and thus implies nonclassical effects, in particular the tunneling.

Table 2. Rate constants at the BHandHLYP/aug-cc-pVTZ level of theory for the most favored $\mathrm{HAT}$ reactions of $\mathrm{CCl}_{3} \mathrm{H}+\mathrm{MO}^{-}(\mathrm{M}=\mathrm{Be}, \mathrm{B}$, and $\mathrm{Al})$ along with the tunneling transmission coefficients as a function of temperature.

\begin{tabular}{|c|c|c|c|c|c|}
\hline \multirow{2}{*}{ System } & \multirow{2}{*}{$T / \mathbf{K}$} & ${ }_{\Delta \mathrm{G}} \neq$ & $k^{\mathrm{TST}}$ & \multirow{2}{*}{$k^{\mathrm{W}}$} & $k(T)$ \\
\hline & & $\left(\mathrm{kJ} \mathrm{mol}^{-1}\right)$ & $\left(\mathrm{L} \mathrm{mol}^{-1} \mathrm{~s}^{-1}\right)$ & & $\left(\mathrm{L} \mathrm{mol}^{-1} \mathrm{~s}^{-1}\right)$ \\
\hline \multirow{8}{*}{$\mathrm{CCl}_{3} \mathrm{H}+\mathrm{BeO}^{-}$} & 298 & \multirow{8}{*}{-78.75} & $2.14 \times 10^{13}$ & 8.37 & $1.79 \times 10^{14}$ \\
\hline & 400 & & $2.63 \times 10^{13}$ & 5.09 & $1.34 \times 10^{14}$ \\
\hline & 500 & & $3.06 \times 10^{13}$ & 3.62 & $1.11 \times 10^{14}$ \\
\hline & 600 & & $3.44 \times 10^{13}$ & 2.82 & $9.70 \times 10^{13}$ \\
\hline & 700 & & $3.79 \times 10^{13}$ & 2.34 & $8.87 \times 10^{13}$ \\
\hline & 800 & & $4.11 \times 10^{13}$ & 2.02 & $8.30 \times 10^{13}$ \\
\hline & 900 & & $4.41 \times 10^{13}$ & 1.81 & $7.98 \times 10^{13}$ \\
\hline & 1000 & & $4.68 \times 10^{13}$ & 1.65 & $7.72 \times 10^{13}$ \\
\hline \multirow{8}{*}{$\mathrm{CCl}_{3} \mathrm{H}+\mathrm{BO}^{-}$} & 298 & \multirow{8}{*}{-27.10} & $1.48 \times 10^{13}$ & 14.65 & $2.17 \times 10^{14}$ \\
\hline & 400 & & $1.74 \times 10^{13}$ & 8.58 & $1.49 \times 10^{14}$ \\
\hline & 500 & & $1.95 \times 10^{13}$ & 5.85 & $1.14 \times 10^{14}$ \\
\hline & 600 & & $2.11 \times 10^{13}$ & 4.37 & $9.22 \times 10^{13}$ \\
\hline & 700 & & $2.24 \times 10^{13}$ & 3.47 & $7.77 \times 10^{13}$ \\
\hline & 800 & & $2.34 \times 10^{13}$ & 2.89 & $6.76 \times 10^{13}$ \\
\hline & 900 & & $2.41 \times 10^{13}$ & 2.50 & $6.03 \times 10^{13}$ \\
\hline & 1000 & & $2.46 \times 10^{13}$ & 2.21 & $5.44 \times 10^{13}$ \\
\hline \multirow{8}{*}{$\mathrm{CCl}_{3} \mathrm{H}+\mathrm{AlO}^{-}$} & 298 & \multirow{8}{*}{-71.13} & $2.04 \times 10^{13}$ & 8.77 & $1.79 \times 10^{14}$ \\
\hline & 400 & & $2.55 \times 10^{13}$ & 5.31 & $1.35 \times 10^{14}$ \\
\hline & 500 & & $2.95 \times 10^{13}$ & 3.76 & $1.11 \times 10^{14}$ \\
\hline & 600 & & $3.32 \times 10^{13}$ & 2.92 & $9.69 \times 10^{13}$ \\
\hline & 700 & & $3.64 \times 10^{13}$ & 2.41 & $8.77 \times 10^{13}$ \\
\hline & 800 & & $3.94 \times 10^{13}$ & 2.08 & $8.20 \times 10^{13}$ \\
\hline & 900 & & $4.22 \times 10^{13}$ & 1.85 & $7.81 \times 10^{13}$ \\
\hline & 1000 & & $4.46 \times 10^{13}$ & 1.69 & $7.54 \times 10^{13}$ \\
\hline
\end{tabular}

$\Delta \mathrm{G}{ }^{\neq}$: TS free energy relative to its corresponding reactants, $k^{\mathrm{TST}}$ : TST rate constant, and $k^{\mathrm{W}}$ : Wigner transmission coefficient. 


\section{CONCLUSIONS}

In summary, from the analysis in the present investigations, we are confident in predicting that, for the HAT reactions of $\mathrm{CCl}_{3} \mathrm{H}+\mathrm{MO}^{-}(\mathrm{M}=\mathrm{Be}, \mathrm{B}$, and $\mathrm{Al})$, (1) the most favored pathway determined in the $\mathrm{BO}^{-}$-reaction is promoted by the $\mathrm{B}$ atom, whereas it becomes the $\mathrm{O}$ atom in both $\mathrm{BeO}^{-}$- and $\mathrm{AlO}^{-}$-reaction. (2) of the three favored pathways obtained here, there is a very striking double-wellpotential character in the channel described consistently by an exothermicity. (3) comparing with $\mathrm{BO}^{-}$case, the $\mathrm{CCl}_{3} \mathrm{H}$ activation in the presence of both $\mathrm{BeO}^{-}$and $\mathrm{AlO}^{-}$becomes very predominant, in which the energy barrier studied for the $\mathrm{C}-\mathrm{H}$ bond dissociation with the assistance of $\mathrm{BeO}^{-}$was found to be low relatively. (4) rate of the favored HAT reactions presented here is governed by the temperature, in which the lower the temperature, the faster the HAT reaction of $\mathrm{BO}^{-}$.

\section{ACKNOWLEDGEMENTS}

We thank for financial support from Natural Science Foundation of Gansu Province (20JR5RA506, 20YF8FA045), National Natural Science Foundation of China (21968032), Northwest Minzu University Chemistry Discipline Innovative Team Construction Project (1110130139,1110130141), Gansu Province First-Class Specialty Construction Project (2019SJYLZY-08).

\section{SUPPORTING INFORMATION}

Energies for the $\mathrm{HAT}$ reactions of $\mathrm{CCl}_{3} \mathrm{H}+\mathrm{MO}^{-}(\mathrm{M}=\mathrm{Be}, \mathrm{B}$, and $\mathrm{Al})$ stationary points.

\section{CONFLICT OF INTEREST}

The author has no conflict of interest.

\section{REFERENCES}

1. W.P. Hu, D.G. Truhlar, J. Am. Chem. Soc. 118, 860 (1996).

2. S.M. Villano, S. Kato, W.C. Lineberger, V.M. Bierbaum, J. Am. Chem. Soc. 128, 736 (2006)

3. S.A. Couchman, N. Holzmann, G. Frenking, D.J.D. Wilson, J.L. Dutton, Dalton Trans. 42, 11375 (2013).

4. K.J. Iversen, S.A. Couchman, D.J.D. Wilson, J.L. Dutton, Coord. Chem. Rev. 40, 297 (2015).

5. B.J. Barker, I.O. Antonov, J.M. Merritt, V.E. Bondybey, M.C. Heaven, R. Dawes, J. Chem. Phys. 137, 214313 (2012).

6. K.J. Mascaritolo, A.R. Dermer, M.L. Green, A.M. Gardner, M.C. Heaven, J. Chem. Phys. 146, 054301 (2017).

7. M.C. Heaven, J. M. Merritt, V.E. Bondybey, Annu. Rev. Phys. Chem. 62, 375 (2011).

8. M.C. Heaven, V.E. Bondybey, J.M. Merritt, A. L. Kaledin, Chem. Phys. Lett. 506, 1 (2011)

9. J.L. Dutton, G. Frenking, Angew. Chem., Int. Ed. 55, 13380 (2016).

10. A. Veldkamp, G. Frenking, Chem. Phys. Lett. 226, 11 (1994).

11. G. Frenking, S. Dapprich, K.F. Koehler;, W. Koch, J.R. Collins, Mol. Phys. 89, 1245 (1996)

12. (a) J.V. Ortiz, Chem. Phys. Lett. 296, 494 (1998). (b) C. Zenouda, P. Blottiau, G. Chambaud, P. Rosmus, J. Mol. Struct. (THEOCHEM) 458, 61 (1999).

13. J.C. Rienstra-Kiracofe, G.S. Tschumper, H.F. Schaefer, S. Nandi, G.B. Ellison, Chem. Rev. 102, 231 (2002).

14. P.G. Wenthold, J.B. Kim, K.L. Jonas, W.C. Lineberger, J. Phys. Chem. A 101, 4472 (1997).

15. F.A. Cotton, G. Wilkinson, C.A. Murillo, M. Bochmann, Advanced Inorganic Chemistry, 6th ed., John Wiley \& Sons: New York (1999).

16. P.M. Hierl, M.J. Henchman, J.F. Paulson, Int. J. Mass Spectrom. Ion Processes 117, 475 (1992)

17. P.M. Hierl, J.F. Paulson, M.J. Henchman, J. Phys. Chem. 99, 15655 (1995).

18. J. Xie, R. Sun, M.R. Siebert, R. Otto, R. Wester, W.L. Hase, J. Phys. Chem. A 117, 7162 (2013).

19. J. Xie, S.C. Kohale, W.L. Hase, S.G. Ard, J.J. Melko, N.S. Shuman, A.A. Viggiano, J. Phys. Chem. A 117, 14019 (2013).

20. S. Ingemann, R.H. Fokkens, N.M.M. Nibbering, J. Org. Chem. 56, 607 (1991).

21. R.N. McDonald, A.K. Chowdhury, D.W. Setser, J. Am. Chem. Soc. 103, 6599 (1981)

22. R.N. McDonald, A.K. Chowdhury, W.D. McGhee J. Am. Chem. Soc. 106, $4112(1984)$

23. Y. Guo, J.J. Grabowski, Int. J. Mass Spectrom. Ion Processes 97, 253 (1990).

24. H.E.K. Matimba, A.M. Crabbendam, S. Ingemann, N.M.M. Nibbering, J. Chem. Soc. Chem. Commun. 9, 644 (1991).
25. Y. Guo, J.J. Grabowski, J. Am. Chem. Soc. 113, 5923 (1991).

26. H.E.K. Matimba, A.M. Crabbendam, S. Ingemann, N.M.M. Nibbering, Int. J. Mass Spectrom. Ion. Processes 114, 85 (1992).

27. M. Born, S. Ingemann, N.M.M. Nibbering, J. Am. Chem. Soc. 116, 7210 (1994).

28. J.-X. Liang, Q. Su, D.-Z. Zhao, Y.-B. Wang, G.-H. Li, Z.-Y. Geng, Heteroatom Chem. 27, 199 (2016)

29. T.D. Hang, M.T. Nguyen, J. Phys. Chem. A 122, 5132 (2018).

30. M.J. Frisch, G.W. Trucks, H.B. Schlegel, G.E. Scuseria, M.A. Robb, J.R Cheeseman, J.A. Montgomery, T. Vreven, Jr., K.N. Kudin, J.C. Burant, J.M. Millam, S.S. Iyengar, J. Tomasi, V. Barone, B. Mennucci, M. Cossi, G. Scalmani, N. Rega, G.A. Petersson, H. Nakatsuji, M. Hada, M. Ehara, K. Toyota, R. Fukuda, J. Hasegawa, M. Ishida, T. Nakajima, Y. Honda, O. Kitao, H. Nakai, M. Klene, X. Li, J.E. Knox, H.P. Hratchian, J.B. Cross, V. Bakken, C. Adamo, J. Jaramillo, R. Gomperts, R.E. Stratmann, O. Yazyev, A.J. Austin, R. Cammi, C. Pomelli, J.W. Ochterski, P.Y. Ayala, K. Morokuma, G.A. Voth, P. Salvador, J.J. Dannenberg, V.G. Zakrzewski, S. Dapprich, A.D. Daniels, M.C. Strain, O. Farkas, D.K. Malick, A.D. Rabuck, K. Raghavachari, J.B. Foresman, J.V. Ortiz, Q. Cui, A.G. Baboul, S. Clifford, J. Cioslowski, B.B. Stefanov, G. Liu, A. Liashenko, P. Piskorz, I. Komaromi, R.L. Martin, D.J. Fox, T. Keith, M.A. Al-Laham, C.Y. Peng, A. Nanayakkara, M. Challacombe, P.M.W. Gill, B. Johnson, W. Chen, M.W. Wong, C. Gonzalez and J.A. Pople, Gaussian 03 (Revision E.01), Gaussian, Inc., Wallingford CT (2004).

31. (a) C. Lee, W. Yang, R.G. Parr, Phys. Rev. B 37, 785 (1988). (b) A.D. Becke, J. Chem. Phys. 98, 1372 (1993).

32. (a) J.-X. Liang, Y.-B. Wang, Q. Zhang, Y. Li, Z.-Y. Geng, X.-H. Wang, J. Mol. Model. 19, 1739 (2013). (b) J.-X. Liang, Q. Su, Y.-B. Wang, Z.-Y. Geng, B. Chem. Soc. Jap. 88, 110 (2015).

33. U. Wille, T. Dreessen, J. Phys. Chem. A 110, 2195 (2006)

34. U. Wille, J.C.-S. Tan, E.K. Mucke, J. Org. Chem. 73, 5821 (2008),

35. S.H. Kyne, C.H. Schiesser, H. Matsubara, J. Org. Chem. 73, 427 (2008)

36. K.J. Mascaritolo, A.R. Dermer, M.L. Green, A.M. Gardner, M.C. Heaven, J. Chem. Phys. 146, 054301 (2017).

37. H.-J. Zhai, L.-M. Wang, S.-D. Li, L.-S. Wang, J. Phys. Chem. A 111, 1030 (2007).

38. P.G. Wenthold, J.B. Kim, K.-L. Jonas, W.C. Lineberger, J. Phys. Chem. A 101, 4472 (1997).

39. R.A. Kendall, T.H. Dunning, Jr., R.J. Harrison, J. Chem. Phys. 96, 6796 (1992).

40. K. Fukui, Acc. Chem. Res. 14, 363 (1981).

41. A.E. Reed, L.A. Curtiss, F. Weinhold, Chem. Rev. 88, 899 (1988)

42. R.M. Parrish, L.A. Burns, D.G.A. Smith, A.C. Simmonett, A.E. DePrince, E.G. Hohenstein, U. Bozkaya, A.Y. Sokolov, R. Di Remigio, R.M. Richard, J.F. Gonthier, A.M. James, H.R. McAlexander, A. Kumar, M. Saitow, X. Wang, B.P. Pritchard, P. Verma, H.F. Schaefer, K. Patkowski, R.A. King, E.F. Valeev, F.A. Evangelista, J.M. Turney, T.D. Crawford, C.D. Sherrill, J. Chem. Theory Comput. 13, 3185 (2017).

43. H.J. Eyring, Chem. Phys. 3, 107 (1935).

44. M.G. Evans, M. Polanyi, Trans. Faraday Soc. 31, 875 (1935).

45. E.J. Wigner, Chem. Phys. 5, 720 (1937).

46. B. Jia, J. Laib, R.F.M. Lobo, P.R. Brooks, J. Am. Chem. Soc. 124, 13896 (2002).

47. A.R. Dermer, M.L. Green, K.J. Mascaritolo, M.C. Heaven, J. Phys. Chem. A 121, 5645 (2017).

48. M.V. Basilevsky, V.M. Ryaboy, Chem. Phys. Lett. 129, 71 (1986).

49. S. Schmatz, D.C. Clary, J. Chem. Phys. 109, 8200 (1998).

50. S. Schmatz, P. Botschwina, J. Hauschildt, R. Schinke, J. Chem. Phys. 117, 9710 (2002).

51. C. Henning, S. Schmatz, J. Chem. Phys. 121, 220 (2004).

52. C. Henning, S. Schmatz, J. Chem. Phys. 122, 234307 (2005)

53. C. Henning, R.B. Oswald, S. Schmatz, J. Phys. Chem. A 110, 3071 (2006).

54. C.-H. Chin, A.M. Mebel, D.-Y. Hwang, J. Phys. Chem. A 108, 473 (2004).

55. E.R. Talaty, Y. Huang, M.E. Zandler, J. Am. Chem. Soc. 113, 779 (1991).

56. M.T. Nguyen, P.J. Groarke, T.-K. Ha, Mol. Phys. 75, 1105 (1992)

57. T.-K. Ha, J. Makarewicz, Chem. Phys. Lett. 299, 637 (1999).

58. C.A. Richards, G. Vacek, B.J. Deleeuw, Y. Yamaguchi, H.F. Schaefer III, J. Chem. Phys. 102, 1280 (1995)

59. J.L. Gole, H.H. Michels, J. Chem. Phys. 103, 7844 (1995).

60. A.I. Boldyrev, J. Simons, J. Chem. Phys. 110, 3765 (1999).

61. M. Sobczyk, I. Anusiewicz, P. Skurski, J. Simons, Mol. Phys. 101, 1259 (2003).

62. K.J. Borve, L.G.M. Pettersson, J. Phys. Chem. 95, 3214 (1991).

63. J.R. Scott, G.S. Groenewold, A.K. Gianotto, M.T. Benson, J. Phys. Chem. A 104, 7079 (2000).

64. T. Baer, W.L. Hase, Unimolecular Reaction Dynamics Theory and Experiments, Oxford: New York (1996).

65. Y. Ren, J.-G. Gai, Y. Xiong, K.H. Lee, S.-Y. Chu, J. Phys. Chem. A 111 6615 (2007). 